\title{
Model Of Local Wisdom Based-Community Empowerment To Control HIV/AIDS In Adolescents
}

\author{
By: ${ }^{1}$ Irwan, \\ irwandel@yahoo.com \\ ${ }^{1}$ Departement Of Public Health, Universitas Negeri Gorontalo, Indonesia
}

\begin{abstract}
The Number of people who living with HIV-AIDS in Gorontalo Province 2019 by age group mostly found in productive age 27-35 years old with the number 128 respondent (74\%). It is estimated that They infected in previous years in adolescence.

The aim of this research is was to develop amodel of risk behavior AIDS disaggregated by gender, the theory of Plan Behavior was used as a framework og the study, Methods of this study was analytic observational study with cross sectional study design. The Sample was 200 students, in the city of Gorontalo, was obtained through purposive random sampling.

The novelty in this research is empowering people based on local wisdom in preventing HIV / AIDS in adolescents The result risk behaviors of AIDS in adolescent behavioral variables not influenced by variables intentions, and beliefs. Model risk behaviors of AIDS showed that variable intention and belief significant effect on behavior, Evaluation models Based on Goodness of fit, teen models on the behavior of otherwise fit the criteria RMSEA value of 0.000 Required $<0.08$. Sugestion In order to prevent HIV and AIDS in adolescents it is recommended to conduct interventions that focus on the religious sector.
\end{abstract}

Key Word: Community empowerment ; HIV/AIDS ; Risk behavior. 


\section{Background}

Based on the population census of 2010 the number of adolescents aged 1019 years by 416 million, or $21 \%$, consisting of 21,110,256 men and $20,492,993$ women of the 210 million population of Indonesia. This is a huge amount of potential human resources if they can be nurtured and prepared early. $(9,12)$

In Gorontalo Province population census data of 2019 reported a population of 3654 souls teens, or there are $14,6 \%$ of the population. The number of cases of HIV and AIDS that have been reported by the KPA from 2001 until the year 2011 are as many as 80 cases, of which there are 10 men and women aged adolescents infected with HIV and AIDS. (12)

Gorontalo Province of cases of HIV and AIDS for the first time with the AIDS status 1 . Until now, with the rapid advancement of the economy and development in the Province of Gorontalo, the increasing number of cases of HIV and AIDS cases is 86 . The number of cases of HIV and AIDS from 2001 to 2019 showed an increase in the addition of new cases, the highest occurred in 2013 found as many as 37 new cases of HIV and AIDS which consists of 28 new HIV cases and 9 cases of AIDS. $\{12\}$

\section{Materials and Methods}

\subsection{Material}

The theory of planned behavior (TPB) is the core factor of individual intention to perform a particular behavior. Intention is assumed as a catcher motivations that influence behavior. In general, the stronger the intention to engage in a behavior, the more likely the behavior is performed, The essence of this theory includes three things: first; beliefs about the likely outcomes and evaluation of the behavior (Behavior beliefs), second; beliefs about the expected norm and motivation to meet these expectations (normative beliefs) third; beliefs about the presence of factors that can support or blocking behavior and awareness of the power of these factors (control beliefs). $(3,4)$

\subsection{Methods}

Methods of this study was analytic observational study with cross sectional study design. The Sample was 200 students, in the city of Gorontalo, was obtained through purposive random sampling. The study population was all teenage high school students city of Gorontalo at least 17 years old at the time of the interview. The multivariate data analysis using structural equation modeling through AMOS program versy 8.50. $(13,22)$

\subsection{Ethical consideration}

Adolescents who were sampled in this study had signed a consent statement before being included in the study Confidentiality of initial information and freedom to withdraw from the study anytimewas stipulated and without any force from the third parties. Those who found to have health concerns will be provided with the appropriate management and informed secretly as necessary

\section{Results}

Characteristics of respondents by sex consisted of 120 male adolescents people, teenage girls 80 people. Respondents based fixed income parents over a period of one month on the lowest income divided by UMR Gorontalo Province in 2013. The results that parents income women all respondents (100\%) income $<750.000$, - each month. While income elderly male respondents highest> 7.5 million as 6 people (6\%). Respondents based on the culture associated with sexual behavior results obtained average with a maximum value of 1.84 and a minimum value of 4 and 1 standard deviation (SD) 0.792 . Teenage boys generally considered good $(95.0 \%)$ culture-related sex behavior, 
only 1 person $(0.8 \%)$ who think that culture is not good. Adolescent girls are generally considered quite good $(81.2 \%)$ culture-related sex behavior, there were 15 men $(18.8 \%)$ who consider the culture well. Respondents based on religious adherence results obtained average with a maximum value of 1.84 and a minimum value of 4 and 1 standard deviation (SD) 0.792 .

Teens practice her faith compliance $102(51 \%)$ is quite obedient, there are 4 people $(2.0 \%)$ which is not adherence to the teachings of his religion. The role of the mass media, there were $97(48.5 \%)$ adolescents considered quite influential media and there were $7(3.5 \%)$ who think the media really has no effect on the results as a whole adolescent knowledge gained through the accumulation of the five aspects of knowledge respondents, the level of overall knowledge in general, including both 149 people $(74.5 \%)$, there are 2 people (1\%) who had no knowledge of either. Standard Deviation (SD) 0.490, 4 maximum value, minimum value of 1 , the average value of 2.22

Juvenile convictions against the consequences of risk behavior (behavior beliefs) average teenager beliefs $=1.99$ with a maximum value of 4 and a minimum value of 1 and a standard deviation (SD) 0535. Confidence adolescent risk behavior resulting from the model and motivation for not doing the behavior (normative beliefs) generally either $156(78.0 \%)$. Average value (normative beliefs) $=1.63$ with a maximum value of 4 and a minimum value of 1 and a standard deviation (SD) 0.629. Juvenile conviction on the surrounding environment does support or hinder the conduct risk behavior are generally classified as either 157 (78.5\%). Adolescent intention to undertake risk behavior include intention to free sex, injecting drug use and wear tattoos or overlap, the results of research in general, including both 116 (56.0\%). The results of the overall behavioral variables in general
119 people $(59.5 \%)$ are not at risk, however there were 60 men $(30 \%)$ very risk. Standard deviation (SD) 1.830, the maximum value of 5 , the minimum value of 1 and a mean value of 2.42. In adolescents economic variables, culture and mass media significantly influence the level of knowledge of adolescents, religious adherence variables significantly influence intention.

Evaluation Based on Goodness of fit models, teen models on the behavior of otherwise fit the criteria RMSEA value of 0.000 Required $<0.08$, then the probability of significant value 0.204 at the end of the model. (13)

\section{Discussion :}

Cultural Influences, Parental Income and Mass Media On Adolescent Knowledge.

In this study the economic, cultural, and the role of mass media are variables that affects adolescent knowledge. The results showed that the economy, the culture, the role of mass media have a positive and significant effect on adolescent knowledge this study support previous research conducted. That adolescents tend to build up knowledge of the information they can from the mass media, friends, and parents. Teens combine their experience and observations, to establish knowledge of adolescents get additional resources for information will develop their understanding of the knowledge, so the more information obtained from a person's level of knowledge of the mass media will be higher. $(6,16,21)$

The role of culture on adolescent knowledge significantly. This study is in line with research conducted by Nicole Crepaz, et al,year which examined the efficacy of Behavior Intervention HIV / STI for African-American Women in the United States: A Meta-Analysis, research the relationship between culture, gender, empowerment, and skills were significant 
predictors of the variable knowledge of African-American adolescent girls are highly correlated with one another SE = $0.15 ; \mathrm{z}=-2.20, \mathrm{P}=.03 .(17,21)$

Cultural influence Mass media and Religious adherence to Intent and Behavior of Adolescents.

Religious compliance significantly affects the intentions of adolescents as a whole Religious values are internalized into human individuals through a gradual process. Starting from a person's acceptance of an ideological understanding then becomes embodied belief into daily behavior. Religious norms are believed to be a group of people that can be the value of community culture is accompanied by rules and sanctions for those who violate. Such societies are often referred to as religious communities. These religious values will continue to be hereditary inherited by the new generation through the process of socialization in institutions in society such as family, social environment, and school. $(17,18$,

The study, conducted by Heubner and Garrod, highlighted the importance of religious and spiritual orientation to morality in Nigerian adolescents, the result of researching that teenagers who have a good spiritual routine to Geraja have a more non-risk sexual orientation. $(8,10)$

Research conducted by Clifford Odimegwu (2005), The influence of religion on adolescent sexual behavior and behavior among Nigerian students The results of the study show there is a strong relationship between religiosity and adolescent sexual behavior and behavior, although religious commitment is more important than religion in influencing attitudes and behavior teenage sex. Because religion influences teenage sexual life, religious leaders can do many things by mobilizing their members to support HIV and AIDS prevention efforts. $(7,20)$
Research conducted by Richard W. Gelles (2001) on 954 Australian adolescents (ages 15-19 years) showed that youths who considered highly religious but less involved in religious activities in the study were at high risk for sexual behavior and drug use. The results show that youth do not use alcohol and do not engage in free sex, as families nurture affection and closeness and when commitment to church and religious centrality are high. (18)

Compliance Relationships Religion Against Intention and Behavior in Adolescents.

Religious adherence significantly influences intention in adolescents. The results are consistent with research conducted by $\mathrm{O}$. Wusu that examines religion, religiosity and adolescent sexual health risk behaviors in Lagos Metropolis, Nigeria survey results collected between December 2009 and February 2010 in the city of Metropolitan Lagos. By multistage sampling method in selecting the 1,026 adolescents between 12 and 19 years, the research reveals that religious affiliation was not significantly associated with sexual intercourse in boys ( $p>0.05$ ), religiosity was significantly associated ( $p$ $<0.05$ ) to multiple sexual partnerships among women in the analysis. The study concludes that religious affiliation does not play a significant role in the fight against sexual risk behavior in adolescent males but religiosity can be quite effective in preventing risk behavior in the female group. $\{7.13,14\}$

Knowledge of beliefs influence behavior, normative beliefs and control beliefs.

The results of knowledge significantly influence adolescent behavior beliefs,. Results of this study showed that the confidence of the consequences if teens do riskier behavior is influenced by the 
level of knowledge of adolescents about HIV and AIDS at 0.807. The better the level of knowledge about HIV and AIDS teens, then teens are increasingly convinced of the impact of such risk behavior can lead to HIV and AIDS. $(2,12)$ The results of knowledge significantly influence adolescent normative beliefs, results of this study showed that the better the level of knowledge about HIV and AIDS adolescents, teenagers are increasingly supporting the belief that other people who are considered influential in adolescents (eg, parents, spouse, friend, or teacher) will refuse or disagree if the teens do riskier behavior. Knowledge level of youth about HIV and AIDS also affects the motivation of young people to follow the opinions of people who are considered influential. $(4,19)$

The results of adolescent knowledge significantly influence control beliefs,. Results of this study showed that the better the level of knowledge about HIV and AIDS by adolescents, the adolescent belief the stronger will be the inhibits risk behavior is to perform, teens who have knowledge about HIV and AIDS will believe that will meet a variety of factors that can inhibit an perform the risk behavior. This belief is based in part by past experience, but also typically influenced also by indirect information about a behavior, by observing the experience of a friend. It is also influenced by other factors that increase or decrease the perception of difficulty to show a certain behavior. $(5,23)$

Beliefs influence behavior, normative beliefs and control beliefs on adolescent intention.

Final modeling results showed that adolescents in adolescents has no effect no significant effect on intentions. The results are inconsistent with the concept of the theory of Planned Behaviour (TPB), which states that the intention is formed by several beliefs (Beliefs) before intentions directly affect behavior. The results are consistent with research conducted by Lin, Huey-Ling, et al. (2012) research on 'new model for predicting sexual intentions in adolescents' relationships between variables analysis showed no significant relationship between beliefs and intention to commit sexual behavior. (11

Intention to influence adolescent behavior.

The results showed that by intention adolescent positive and significant impact on risk behavior. Results of this study showed that the intention to conduct HIV and AIDS risk behaviors in adolescents is not significantly influenced by beliefs, as proposed by Ajzen and Fishbein (1988) in the TPB theory, $\{15\}$ so the results of this study rejected TPB theoretical concept which states that a person's intention to perform a particular behavior is built or formed from multiple beliefs (beliefs). The results showed that adolescents intention to conduct HIV and AIDS risk behaviors were significantly affected by adolescent compliance in practice her faith with coefficient factors 0.570 and $\rho<0.001$.

Ajzen defines intention as a behavioral disposition that until there is the right time and opportunity, will be manifested in the form of action. In line with the definition Friedman S (2003) states intentions are individual plans or resolutions to carry out behavior appropriate to their attitudes. Intention is also defined as an internal declaration to act. (11)

Ther studies showing the
relationship between intention and
adolescent behavior such as those conducted by Lin, Huey-Ling, et al (2012) examined the new model in predicting sexual intentions in adolescents in America. The results of the study have a positive direct relationship between adolescent sexual behavior and their 
sexual intentions. Teens who have experienced sexual experience are more likely to express the intention to have sexual intercourse in the near future.(1)

\section{Conclusion :}

HIV and AIDS risk behaviors in adolescents is influenced by intention and religious compliance

\section{Acknowledgements :}

The authors wish to acknowledge the contributions of Teachers and Parents in the city of Gorontalo are willing to be respondents in this study. Acknowledgments to the head of Gorontalo City education office who provided data support during the study.

\section{Bibliography}

1. Adams, G. R., \& Gullota. T. (1983). Adolescent life experiences. New York: Brooks / / Cole; Pacific Groves, CA., (1st. Ed., 1983; 2nd.Ed., 1989, 3rd. Ed., 1993) Cloe Publishing Company. www.uoguelph.ca/ gadams / adamsweb / cvpublic.htm

2. Anderson J.et.al. (1990). HIV/AIDS Knowledge and Sexual Behavior Among High School Students. Journal of Family Planning Perspectives. Vol 22, No. 6, pp. 252-255. up date 3 Maret 2012 (Acessed dated Mei 23, 2017)

3. Ajzen, I. and Fishbein, M. (1980) Efficacy of the Theory of Planned Behaviour: A meta analysis review in: British Journal of social psychology 2011,40,471-499, Great Britian: The British psychological society.

4. ........ (1988) Changg ing the Behavior of People, Explanation of Theory of Planned Behaviour. Manage the Executive Journal 12 fast track. Available at: http:/www.12manage.com (accessed dated June 22, 2017)

5. Alexander, Lisa T, (2011). Cultural Collective Efficacy, Social Capital and Placed-Based Lawmaking: Revisiting the People Versus Place Debate. http://ssrn.com/abstract $=1920364$ (Accesed dated juni 20, 2017).

6. Anderson J.et.al. (1990). HIV / AIDS Knowledge and Sexual behavior Students Among high school. Journal of Family planning perspectives. 22. (6) .252-255. Up date March 3, 2012 (accesed of dated June 26, 2017).

7. Bandura A. (2011) Social Foundation of Thought and Action: A Social Cognitive Theory, Englewood Cliffs, N.Journal: Prentice Hall: 1986 24-46

8. Benda, Bren t. (1995) The Effect of Religion on Adolescent delinquency Revisited.incomplete reference

9. Central Statistics Agency (BPS) Gorontalo Province (2015), Gorontalo in numbers.

10. Cochran et.al.(2000) Beyond Hellfire: An Exploration of the Variable Effects of Religiosity on Adolescent Marijuana and Alcohol Use. Journal of Research in Crime and Delinquency. Vol. 26 (2000) pp. 198-225.

11. Friedman,S (2003) HIV Prevalence, Risk Behaviours, and High-Risk Sexual and Injection Networks Among Young Women Injectors Who Have Sex With Women. Journal Public Health. 2003 June; Vol. 93, No.6, pp. 902906. http://www.ncbi.nlm.nih.gov (Acessed dated, Juli 16, 2017)

12. Gorontalo Provincial Health Office (2015). Health Profile of Gorontalo Province.

13. Ghozali, initial(s) (2004). Structural Equation Modeling, Concepts and Applications 
premises AMOS 19.0 program, issue 1, Diponegoro University, Semarang

14. Huebner, A. \& Garrod, A. (1991). Equilibration and the Learning Paradox . Human development, 34, 261-272.

15. Irwan ; Model of Hypertension

Transmission Risks to

Communities in Gorontalo

Province ; Indian Journalof Public

Health Research \& Development

Volume 9 Nomor 1 Januari 2018

http://www.indianjournals.com/IJOR.ASP

$\underline{X}$ ?target=ijor:ijphrd\&volume $=9 \&$ issue $=1 \&$ article $=058$

16. M. Katherine Hutchinson \& Elyssa

B. Wood. (2000)

Reconceptualizing Adolescent

Sexual Risk In A Parent-Based

Expansion Of The Theory Of

Planned Behavior. Medicine -

Miscellaneous Papers

17. Notoatmodjo, Soekidjo, (2010).

Health promotion, theory and applications, Rineka Cipta, Jakarta

18. O' Wusu initial (2011) Religion, Religiosity and Adolescend Sexual health risk s behaviors in Lagos Metropolis Nigeria. Journal of Humanities and social science. http://www.ajol.info/index.php/ijhs s/article/view/69507.(accessed on Mei 27, 2017)

19. Richard W. Gelles (2001): Adolescent Risk Behaviors and Religion: Findings from a National
Study of University of

Pennsylvania scholarly Commons

Published in the Journal of

Adolescence, Volume 30, Issue 2,

April 2007, 231-249 ages.

Publisher URL:

http://dx.doi.org/10.1016/j.adolesce nce.2006.02.005

20. Robert Mallow et.al. (2006)

Intervention and Patterns in

Adolescend HIV/AIDS Prevention.

Journal Institude Of Health NIH

Public Access. publish 15

Desember 2008 (Acessed dated

Juni 26, 2017).

21. Santrock J.W. (2003): Adolescend, Adolescent Development. (Shinto B.Adelar \& Sherly Saragih, Translators, Jakarta Airlangga.

22. Scholly. K.et.al (2005) : Using social norms theory to Explain Perceptions and Sexual Health Behaviours of Undergraduate college Students: an Exploratory study, Journal of American College Health. Vol. 53, No. 4 2005, pp. 159-166.

23. Supriyanto, S and A.J. Djohan (2011) Business Research Methodology and Health, publisher of Graphic Wangi PT Kalimantan, Banjarmasin.

24. Solita, S. (2004) Sociology of Health, Some Concepts and Their Application, Gadjah Mada University Press, Yogyakarta 


\section{Additional files}

Additional files A : Final Model of Path Analysis in adolescent

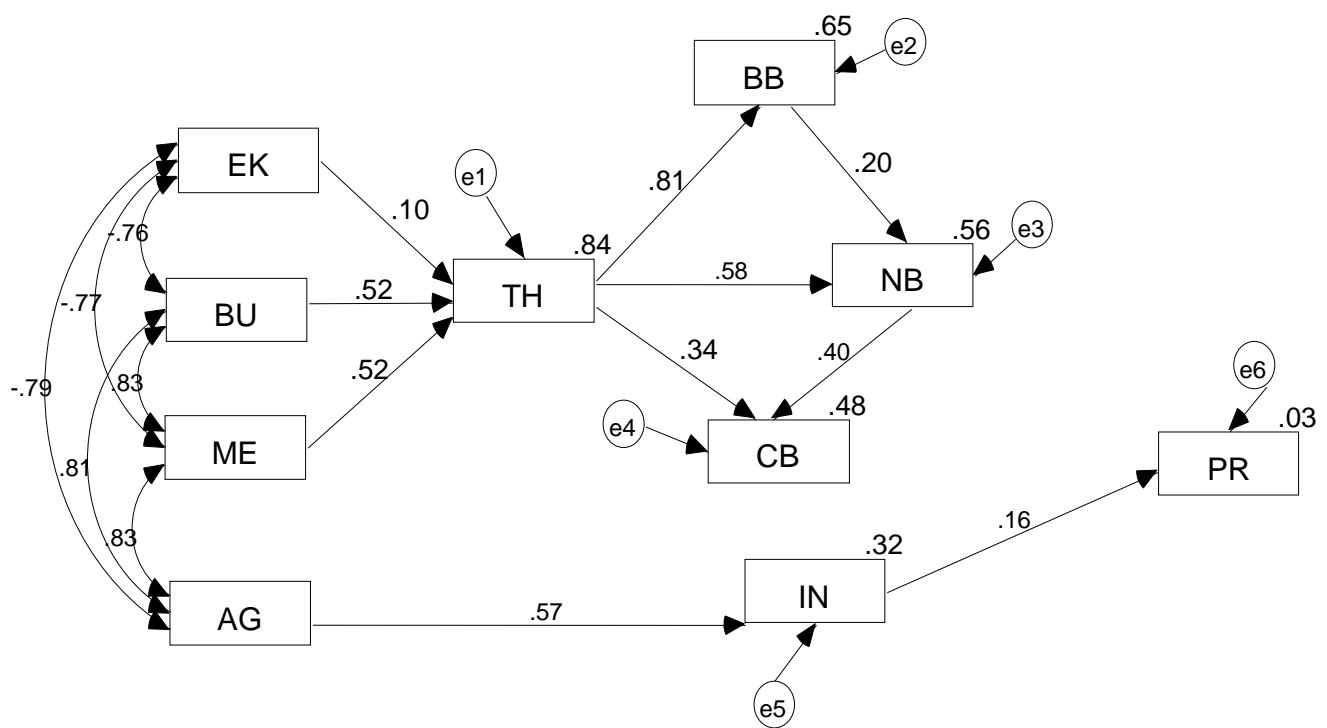

Additional files B. The relationship between variable model of adolescent behavior in Gorontalo.

\begin{tabular}{|l|c|c|c|}
\hline \multicolumn{1}{|c|}{ Significant } & $\beta$ & $\rho$ & Description \\
\hline TH $\rightarrow$ B B & 0,807 & 0,001 & Significan \\
TH $\rightarrow$ NB & 0,578 & 0,001 & Signif ican \\
TH $\rightarrow$ CB & 0,339 & 0,001 & Significan \\
B B NB & 0,198 & 0,001 & Significan \\
NB $\rightarrow$ CB & 0,401 & 0,021 & Significan \\
IN $\rightarrow$ PR & 0,163 & 0,020 & Description \\
\hline \multicolumn{1}{|c|}{ Significant } & $\lambda$ & $\rho$ & Significan \\
\hline BU $\rightarrow$ TH & 0,520 & 0,001 & Significan \\
ME $\rightarrow$ TH & 0,521 & 0,001 & Signifikan \\
EK $\rightarrow$ TH & 0,100 & 0,035 & Significan \\
AG $\rightarrow$ IN & 0,570 & 0,001 & \\
\hline
\end{tabular}

Additional files C. Testing Models

\begin{tabular}{lcc}
\hline Goodness of fit indeks & Cut of Value & Final models \\
\hline Chi Square & & \\
\hline Sigificant probability & 0.001 & 0,001 \\
\hline CMN/DF & diharapkan kecil = df & 29 \\
\hline GFI & $<2.0$ & 0.051 \\
\hline RMSEA & $>0.90$ & 0,915 \\
\hline NFI & $<0.08$ & 0,124 \\
\hline RMR & $>0.90$ & 0.934 \\
\hline
\end{tabular}

